\title{
Complementary Roles of Cholecystokinin- and Parvalbumin- Expressing GABAergic Neurons in Hippocampal Network Oscillations
}

\author{
Thomas Klausberger, ${ }^{1,2}$ Laszlo F. Marton, ${ }^{1}$ Joseph 0 'Neill, ${ }^{1}$ Jojanneke H. J. Huck, ${ }^{1}$ Yannis Dalezios, ${ }^{1}$ Pablo Fuentealba, ${ }^{1}$ \\ Wai Yee Suen, ${ }^{1}$ Edit Papp, ${ }^{1}$ Takeshi Kaneko, ${ }^{3}$ Masahiko Watanabe, ${ }^{4}$ Jozsef Csicsvari, ${ }^{1}$ and Peter Somogyi ${ }^{1}$ \\ ${ }^{1}$ Medical Research Council Anatomical Neuropharmacology Unit, Oxford University, Oxford OX1 3TH, United Kingdom, ${ }^{2}$ Center for Brain Research, \\ Medical University, 1090 Vienna, Austria, ${ }^{3}$ Department of Morphological Brain Science, Graduate School of Medicine, Kyoto University, 606-8501 Kyoto, \\ Japan, and ${ }^{4}$ Department of Anatomy, Hokkaido University School of Medicine, 060-3638 Sapporo, Japan
}

In the hippocampal CA1 area, a relatively homogenous population of pyramidal cells is accompanied by a diversity of GABAergic interneurons. Previously, we found that parvalbumin-expressing basket, axo-axonic, bistratified, and oriens-lacunosum moleculare cells, innervating different domains of pyramidal cells, have distinct firing patterns during network oscillations in vivo. A second family of interneurons, expressing cholecystokinin but not parvalbumin, is known to target the same domains of pyramidal cells as do the parvalbumin cells. To test the temporal activity of these independent and parallel GABAergic inputs, we recorded the precise spike timing of identified cholecystokinin interneurons during hippocampal network oscillations in anesthetized rats and determined their molecular expression profiles and synaptic targets. The cells were cannabinoid receptor type 1 immunopositive. Contrary to the stereotyped firing of parvalbumin interneurons, cholecystokinin-expressing basket and dendrite-innervating cells discharge, on average, with $1.7 \pm 2.0 \mathrm{~Hz}$ during high-frequency ripple oscillations in an episode-dependent manner. During theta oscillations, cholecystokinin-expressing interneurons fire with $8.8 \pm 3.3 \mathrm{~Hz}$ at a characteristic time on the ascending phase of theta waves $\left(155 \pm 81^{\circ}\right)$, when place cells start firing in freely moving animals. The firing patterns of some interneurons recorded in drug-free behaving rats were similar to cholecystokinin cells in anesthetized animals. Our results demonstrate that cholecystokinin- and parvalbumin-expressing interneurons make different contributions to network oscillations and play distinct roles in different brain states. We suggest that the specific spike timing of cholecystokinin interneurons and their sensitivity to endocannabinoids might contribute to differentiate subgroups of pyramidal cells forming neuronal assemblies, whereas parvalbumin interneurons contribute to synchronizing the entire network.

Key words: hippocampus; interneurons; cholecystokinin; theta oscillations; ripple oscillations; endocannabinoids; sparse coding

\section{Introduction}

Information processing in the cerebral cortex is structured by the occurrence of network oscillations (Buzsaki and Draguhn, 2004). The frequencies of these oscillations depend on the brain state and behavior of the animal. In the hippocampus, theta $(4-10 \mathrm{~Hz})$ oscillations occur during exploratory behavior and rapid eye movement sleep (Grastyan et al., 1959; Vanderwolf, 1969; O'Keefe and Recce, 1993; Soltesz and Deschenes, 1993). Sharp wave-associated high-frequency ripples $(120-200 \mathrm{~Hz})$ of $\sim 100$

Received April 20, 2005; revised Sept. 8, 2005; accepted Sept. 9, 2005.

T.K. was supported by Grant P16637 from the Austrian Science Fund. We thank J. David B. Roberts for help with histology and electron microscopy, Dr. Agnes Baude and Marta Hernandez for histological assistance, Dr. I. HuertaOcampo for help with electron microscopy, Drs. S. Jinno and Jozsef Somogyi with confocal microscopy, and E. Kovacs for help with cell reconstruction. We are grateful to Drs. K. Baimbridge, Tamas Gorcs, S. El Mestikawy, E. Mugnaini, R. Shigemoto, W. Sieghart, A. Varro, and the CURE/Digestive Diseases Research Center, Antibody/RIA Core at University of California, Los Angeles for the gift of antibodies (see supplemental Table 1, available at www.jneurosci.org as supplemental material).

Correspondence should be addressed to Thomas Klausberger, Medical Research Council Anatomical Neuropharmacology Unit, Oxford University, Mansfield Road, 0xford OX1 3TH, UK. E-mail: thomas.klausberger@ pharm.ox.ac.uk.

DOI:10.1523/JNEUROSCI.3269-05.2005

Copyright $\odot 2005$ Society for Neuroscience $\quad 0270-6474 / 05 / 259782-12 \$ 15.00 / 0$ ms duration occur during slow-wave sleep, awake inactivity, and consummatory behaviors (Buzsaki et al., 1983). These oscillations reflect the summed activity of pyramidal cells and interneurons, which fire rhythmically during the oscillations. Pyramidal cell firing carries the information, whereas interneurons releasing GABA are likely to play a role in temporal modulation, perhaps explaining their large diversity.

The existence of many distinct GABAergic interneuron classes, innervating distinct domains of pyramidal cells, is a hallmark of the cerebral cortex (Ramon y Cajal, 1893; McBain and Fisahn, 2001; Pouille and Scanziani, 2004; Toledo-Rodriguez et al., 2004; Somogyi and Klausberger, 2005). In the hippocampus, basket, axo-axonic, bistratified, and oriens-lacunosum moleculare (O-LM) cells innervate pyramidal cells mainly on the soma, axon initial segment, and dendrites in stratum radiatum/oriens or lacunosum moleculare, respectively, and all these cells express parvalbumin (PV). The weak expression of PV by O-LM cells was reported both from a small sample of in vivo recorded cells (Klausberger et al., 2003) and a population survey (Ferraguti et al., 2004). The spatial specialization in axonal targeting is accompanied by molecular and biophysical differentiation supporting 
the precise spatiotemporal delivery and action of GABA (Jonas et al., 2004; Mody and Pearce, 2004). We have shown that each type of parvalbumin-expressing interneuron fired with distinct stereotyped pattern during theta and ripple oscillations (Klausberger et al., 2003, 2004). But, in addition to the PV-expressing cells, other types of GABAergic interneuron, expressing cholecystokinin (CCK) (Somogyi et al., 1984), also provide parallel innervation to the somatic or different dendritic domains of pyramidal cells (Harris et al., 1985; Nunzi et al., 1985; Cope et al., 2002; Pawelzik et al., 2002; Kawaguchi and Kondo, 2002). The CCKexpressing interneurons show several distinct axonal patterns (Cope et al., 2002; Pawelzik et al., 2002). In contrast to PVexpressing cells, some CCK interneurons also express vasoactive intestinal polypeptide (VIP), cannabinoid receptor type 1 (CB1), vesicular glutamate transporter type 3 (VGLUT3), a high level of somatic $\mathrm{GABA}_{\mathrm{B}}$ receptors, and $5-\mathrm{HT}_{3}$ receptors, and their postsynaptic action is probably mediated mainly by $\alpha 2$ subunitcontaining $\mathrm{GABA}_{\mathrm{A}}$ receptors (for review, see Freund, 2003). The differential design of CCK- and PV-expressing interneurons raises the possibility that they release GABA to pyramidal cells at different times or in different brain states. We have tested this hypothesis by recording the in vivo firing patterns of identified CCK-expressing interneurons in anesthetized rats and comparing their spike timing during oscillations with that of PVexpressing cells innervating the same subcellular domain of pyramidal cells. We also recorded interneurons in behaving animals to see whether the firing patterns recorded under anesthesia exist in drug-free conditions.

\section{Materials and Methods}

In vivo recordings and labeling. All procedures involving experimental animals were performed in accordance with the Animals (Scientific Procedures) Act, 1986 (UK) and associated regulations under approved project licenses. Male Sprague Dawley rats $(250-350 \mathrm{~g})$ were anesthetized with $1.25 \mathrm{~g} / \mathrm{kg}$ of body weight urethane plus supplemental doses of ketamine and xylazine (20 and $2 \mathrm{mg} / \mathrm{kg}$, respectively) as needed; body temperature was maintained with a heating pad. Neuronal activity in the hippocampus was recorded extracellularly with a glass electrode $(18-25$ $\mathrm{M} \Omega$ ) filled with $1.5 \%$ neurobiotin in $0.5 \mathrm{M} \mathrm{NaCl}$, and the local field potential (lfp) was recorded with a second angled glass electrode in the hippocampal CA1 pyramidal cell layer at a similar anteroposterior and mediolateral position. The local field potential was always identical in both electrodes in the pyramidal layer, but there was a $180^{\circ}$ phase shift of theta oscillations and sharp waves at stratum radiatum when recorded with the electrode used for searching for interneurons. Single-unit activity (sampling rate, $20 \mathrm{kHz}$ ) and lfp (sampling rate, 800 or $1000 \mathrm{~Hz}$ ) were filtered on-line between 0.8 and $5 \mathrm{kHz}$ and dc-220 or $0.3-300 \mathrm{~Hz}$, respectively. Putative interneurons were distinguished from putative pyramidal cells by the lack of complex spike bursts, narrow spike width, or sometimes only by a conspicuous firing pattern like high firing frequencies during theta oscillations (Csicsvari et al., 1999). We tried to record and label all putative interneurons to avoid cell sampling bias for CCKexpressing cells with a particular firing pattern only. Recorded cells were individually labeled with neurobiotin only after data for the firing patterns had been sampled using the juxtacellular-labeling method (Pinault, 1996). Recordings from eight of nine CCK-expressing interneurons resulted in a single labeled interneuron after histological processing. In one case, spikes from a putative interneuron and a putative pyramidal cell were recorded simultaneously, and, after labeling, a CCK-positive interneuron (T99d) and a pyramidal cell were recovered.

Tissue processing and anatomical analysis. The rats were perfused with fixative ( $4 \%$ paraformaldehyde, $0.05-0.1 \%$ glutaraldehyde, $15 \%$ v/v saturated picric acid) $\sim 4 \mathrm{~h}$ after labeling. Reconstruction of cells was performed using 63 or $100 \times$ oil immersion objectives and a drawing tube from peroxidase-reacted brain sections (Klausberger et al., 2003).

For immunofluorescence reactions, mixtures of up to three primary or secondary antibodies raised in different species were used as described previously (Somogyi et al., 2004) and listed in supplemental Table 1 (available at www.jneurosci.org as supplemental material), together with references for antibody specificity. The initial choice of antibodies was governed by the likely occurrence of a molecule before the identity of the cell type was known. Therefore, some molecules such as somatostatin (SOM) or neuropeptide tyrosine (NPY), which are not known to be coexpressed with CCK, were tested only in few cells. Subsequent tests were performed for comparison with other cell types, but in some cases, the test either failed or there was no tissue available for testing all the molecules. Cells were considered immunonegative for a molecule when fluorescence was undetectable in the tested part of the cell (soma and/or dendrite and/or axon terminal) in an area where similar parts of other unrecorded cells were immunopositive. If it could not be clearly decided by a consensus of two or three investigators whether the cell was immunonegative or immunopositive (occasionally because of background labeling), the test was considered inconclusive and the appropriate space is left blank in Table 1. Method specificity was tested by omitting the primary antibodies in the incubation sequence. To test antibody specificity, antisera against metabotropic glutamate receptor $1 \alpha(\mathrm{mGluR} 1 \alpha)$, mGluR7a, and mGluR8a used in this study were tested on brain sections of mice lacking the respective receptor (brains of receptor-null mice were kindly provided by Drs. F. Conquet, R. Duvoisin, and H. Van der Putten to Dr. F. Ferraguti, Innsbruck University, Innsbruck, Austria who tested the antibodies). No immunolabeling for any of these antibodies could be detected in sections of mice lacking the respective receptor (data not shown). To control for a possible cross-reactivity between IgGs in double- and triple-immunolabeling experiments, some sections were processed through the same immunocytochemical sequence, except that only one primary antibody was applied, but the full complement of secondary antibodies was maintained. In addition, the secondary antibodies used were highly preadsorbed to the IgGs of numerous species.

All efferent synapses made by CCK cells in the plane of the section were photographed in the electron microscopic analysis ensuring random sampling, and postsynaptic targets were identified. Pyramidal cell dendrites were identified by electron-opaque intracellular protein aggregates, emerging dendritic spines, and absence of type I synapses onto dendritic shafts. Dendritic spines were identified by their specific shape emerging from a dendrite, a single type I synapse, sometimes the presence of spine apparatus, and the absence of microtubuli. Interneurons were defined by type I synapses on postsynaptic dendritic shafts and lack of dendritic spines.

To determine the bouton size, we used light microscopy on Tritontreated sections. Boutons were randomly collected digitally and after contrast enhancement analyzed using Image (1.33u; Wayne Rasband, National Institutes of Health, Bethesda, MD). Bouton size is characterized by the two-dimensional projected area.

Statistical analysis of physiological data. Theta epochs were detected by calculating the theta $(3-6 \mathrm{~Hz})$ to $\delta(2-3 \mathrm{~Hz})$ ratio in $2 \mathrm{~s}$ windows of the lfp (Csicsvari et al., 1999). Ratio $>4$ in at least three consecutive windows marked theta episodes, and ratio $<2$ in at least three consecutive windows indicated non-theta/non-sharp wave periods; the ripple episodes were not included in spike counts for non-theta/non-sharp wave periods. Episodes with intermediate ratio were not included in the analysis. To determine the phase relationship between single-cell activity and theta, the local field potential during theta episodes was filtered between 3 and $6 \mathrm{~Hz}$, and the troughs of the theta oscillations were detected in the filtered signals. Each spike was assigned to a given phase (bin size, $20^{\circ}$ ) between the troughs, and all theta cycles were superimposed (Csicsvari et al., 1999).

For the detection of sharp wave-associated ripples, the lfp was filtered between 90 and $140 \mathrm{~Hz}$, and the power (root mean square amplitude) of the filtered signal was calculated in $10 \mathrm{~ms}$ windows (Csicsvari et al., 1999). The threshold for ripple detection was set to 5 SD above the mean power. Beginning and end of the sharp wave were set where the power crossed $1 \mathrm{SD}$ above the mean power; the peak of the sharp wave was detected by a simple peak-finding algorithm. To evaluate the firing pat- 
terns of a single neuron during sharp waves, these episodes were superimposed by normalization. For all spikes that occurred before the peak of the sharp wave, the time between the beginning and the peak of the sharp wave was normalized into four bins. For all spikes that occurred after the peak of the sharp wave, the time was normalized between the peak and the end of the sharp wave into four additional bins.

The discharge frequency of single cells during three different brain states (theta, sharp wave, and non-theta/nonsharp wave) was calculated by dividing the number of spikes by the summed time of the respective brain state.

Data are given as mean \pm SD or mean angle \pm angular deviation throughout the manuscript. Theta phase was described and compared using circular statistics (Zar, 1999).

Recordings in nonanesthetized rats. Six male rats were implanted with four to eight independently movable wire tetrodes under deep anesthesia using isoflurane $(0.5-3 \%)$, oxygen (1-2 $\mathrm{L} / \mathrm{min}$ ), and an initial dose of buprenorphine $(0.3 \mathrm{ml} / \mathrm{kg})$. Tetrodes were attached to microdrives, enabling the independent movement of all the electrodes. Tetrodes were constructed from four tungsten wires, $12 \mu \mathrm{m}$ in diameter (California Fine Wire, Grover Beach, CA), with gold-plated tips to reduce the electrode impedance to $200-400 \mathrm{k} \Omega$. The electrode bundles were positioned above the dorsal hippocampus. The head implant was attached to the scull with dental acrylic and stainless-steel screws.

After a recovery period of $7 \mathrm{~d}$, the tetrodes were lowered into the hippocampus over a period of up to $7 \mathrm{~d}$. Wide-band $(1 \mathrm{~Hz}-5 \mathrm{kHz})$ recordings were taken, and the amplified extracellular field $[1000 \times$; via a 64 channel Sensorium (Charlotte, VT) amplifier] and action potentials were digitized continuously at $20 \mathrm{kHz}$ using a 64 channel analog-to-digital converter computer card (United Electronics Industries, Canton, MA). Unit isolation and clustering procedures have been described previously (Csicsvari et al., 1999). Briefly, spikes were extracted from the digitally high-pass-filtered $(0.8-5 \mathrm{kHz})$ signal and spike features extracted using principal components analyses. The detected action potentials were then segregated into putative multiple single units using an automatic clustering software (Harris et al., 2001) (http://klustakwik.sourceforge.net/). Finally, the generated clusters were manually refined by a graphical cluster-cutting program. Only units with clear refractory periods in their autocorrelation and well defined cluster boundaries were used for additional analysis. Putative interneurons were identified by their autocorrelations and wave forms, as described previously (Csicsvari et al., 1999).

Theta oscillations were detected during exploration sessions. Theta epochs were selected by calculating the ratio of Fourier components of theta $(5-12 \mathrm{~Hz})$ and $\delta(2-4 \mathrm{~Hz})$ frequency bands, and the negative peaks of individual theta waves were detected in digitally filtered $(5-28 \mathrm{~Hz})$ signal. The theta phase histogram of the putative interneurons during exploration was calculated as outlined above for the acute procedures. Sharp waves/ripples were detected during non-theta sleep periods by calculating the power (root mean square) of $150-250 \mathrm{~Hz}$ bandpassfiltered signal. Detection threshold was set to 7 SD from the baseline mean. Firing histograms during ripple episodes were calculated using the same methodology as described for the acute experiments.

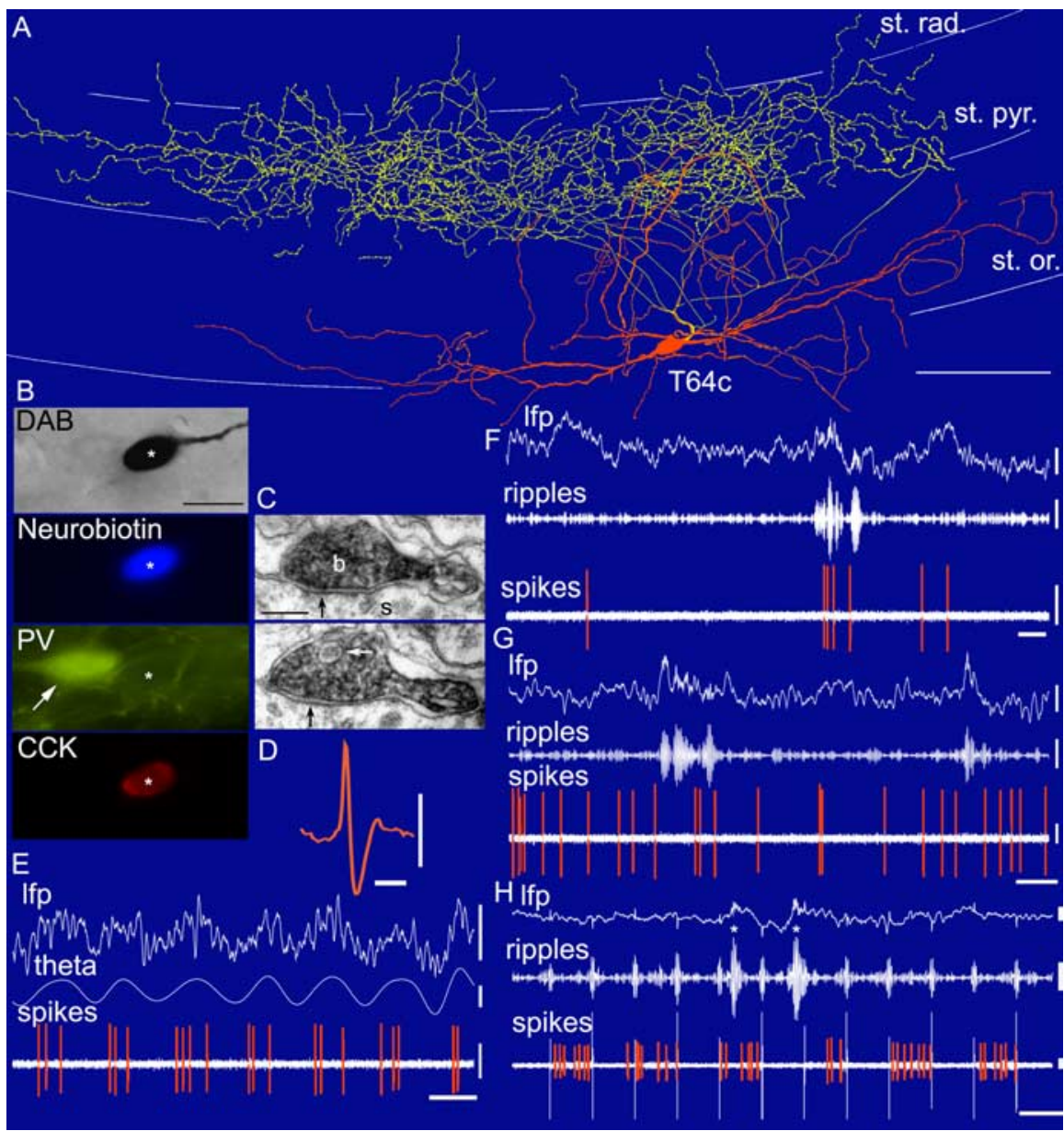

Figure 1. In vivo firing patterns and visualization of a (CK-expressing basket cell (T64C). A, Reconstruction of the soma and dendrites (orange) is shown complete; the axon (yellow) is shown only from three sections of $65 \mu \mathrm{m}$ thickness for clarity. st. rad. Stratum radiatum; st. pyr., stratum pyramidale; st. or., stratum oriens. Scale bar, $100 \mu \mathrm{m}$. $\boldsymbol{B}$, Light (DAB reaction) and immuno( episodes (filtered between 90 and $140 \mathrm{~Hz}$ ), the cell was sometimes activated $(\boldsymbol{F})$ and sometimes silenced (G). During the labeling, positive current was applied in $200 \mathrm{~ms}$ on/off mode $(\boldsymbol{H})$, modulating the firing of the cell. Note that a ripple episode during the current-on phase silenced the cell. Asterisks mark true ripple episodes, whereas other fast oscillations are artifacts of current steps. Ifp, $0.3-200 \mathrm{~Hz}$. Calibration: Ifp, $0.5 \mathrm{mV}$; theta, $0.2 \mathrm{mV}$ and $0.2 \mathrm{~s}$; ripples, $0.1 \mathrm{mV}$ and $0.2 \mathrm{~s}$; spikes, $0.5 \mathrm{mV}$.

\section{Results}

To determine the in vivo firing patterns of CCK-expressing interneurons, we recorded single cells extracellularly in the hippocampal CA1 area of anesthetized rats during different brain states. We labeled 79 of the recorded interneurons with neurobiotin for identification [ 17 of these cells have been published by Klausberger et al. (2003, 2004)]. Using immunofluorescence analysis, we demonstrated the expression of CCK in the soma of nine interneurons from nine different animals (Figs. $1 B, 2 B, 3 C, 4 D$ ) from a sample of 36 cells tested for CCK. In four additional cases, the immunocytochemical test failed and the other cells were not tested for CCK, because the first immunoreaction and/or their processes identified them as, for example, O-LM cells or PV basket cells, which are known not to express CCK. We analyzed the dendritic and axonal distributions, synaptic connectivity, expres- 


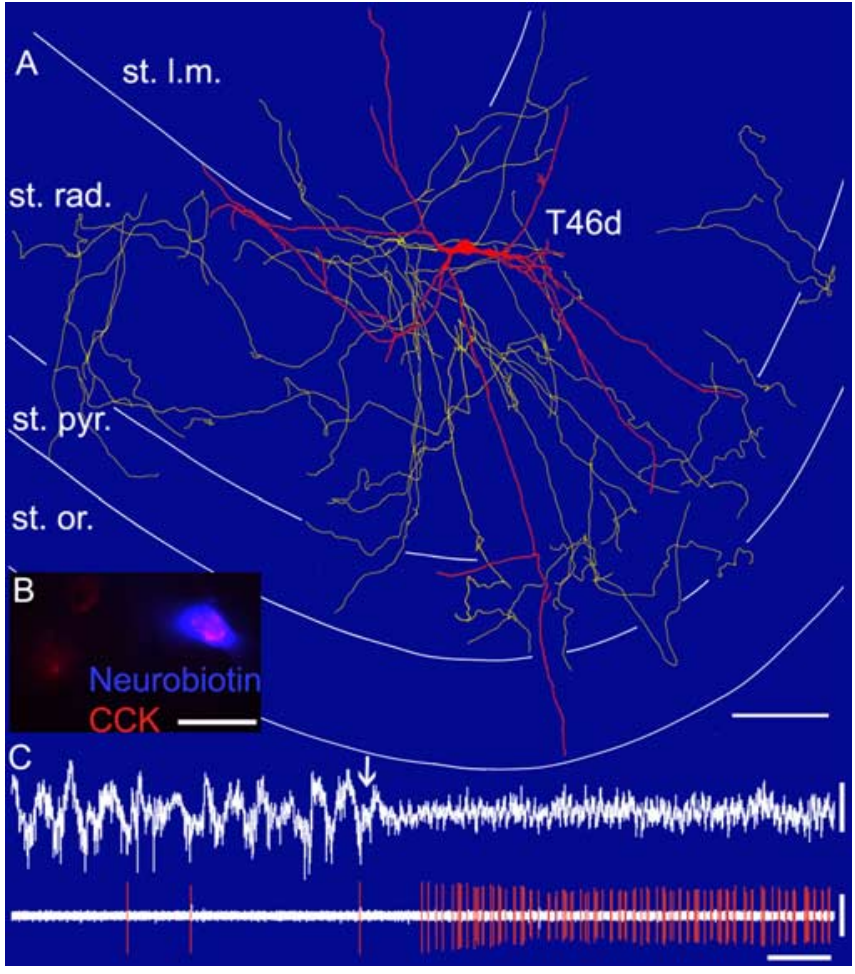

Figure 2. In vivo firing patterns and visualization of a CCK-expressing, apical dendriteinnervating cell (T46d). $\boldsymbol{A}$, Reconstruction of the soma and dendrites (orange) is shown complete; the axon (yellow) is shown only from three sections of $65 \mu \mathrm{m}$ thickness for clarity. st. rad. Stratum radiatum; st. pyr., stratum pyramidale; st. or., stratum oriens; st. I.m., stratum lacunosum moleculare. Scale bar, $100 \mu \mathrm{m}$. B, Superimposed immunofluorescence micrograph of the neurobiotin-labeled cell (blue) and CCK (red) immunoreactivity in the Golgi apparatus. Scale bar, $20 \mu \mathrm{m}$. C, In vivo firing patterns of the cell. Note that during the initial slow oscillation, the cell fired very rarely, but after a light foot pinch (arrow), the local field potential changed to theta oscillation and the cell strongly increased its firing rate. Calibration: Ifp and spikes, $1 \mathrm{mV}, 2 \mathrm{~s}$.

sion of molecules involved in signaling, and the spike timing of CCK-expressing interneurons during network oscillations.

Expression of receptors, neuropeptides, and $\mathrm{Ca}^{2+}$-binding proteins in CCK-positive cells

The GABAergic phenotype of five tested CCK-expressing interneurons was confirmed by immunoreaction (Table 1) for glutamate decarboxylase. The axonal membrane of CCK-expressing interneurons was outlined by cannabinoid receptor CB1 immunoreactivity (four of four cells tested) (Figs. 4D, 5A). Three of seven tested cells were positive for VIP, and two of these were identified as basket cells. Two of three tested neurons, both of them basket cells, were immunopositive for pre-protachykinin B (PPTB). Two of five cells tested for VGLUT3 were positive (Fig. $5 A$ ), and two of five cells tested were immunopositive for the neurokinin-1 receptor in their dendritic membrane. Calbindin immunoreactivity was found in one of five tested cells. Weak mGluR $1 \alpha$ immunoreactivity was detected in the dendritic membrane of one of eight tested CCK interneurons (Table 1). No immunoreactivity was detected in CCK-expressing interneurons for somatostatin (one cell tested), NPY (three cells tested), corticotropin-releasing factor (one cell tested), PV (seven cells tested), calretinin (five cells tested), $\mathrm{GABA}_{\mathrm{A}}$ receptor $\alpha 1$ subunit (five cell tested), in the input terminals for mGluR7a (one cell tested) and mGluR8a (one cell tested), and nitric oxide synthase (five cells tested).

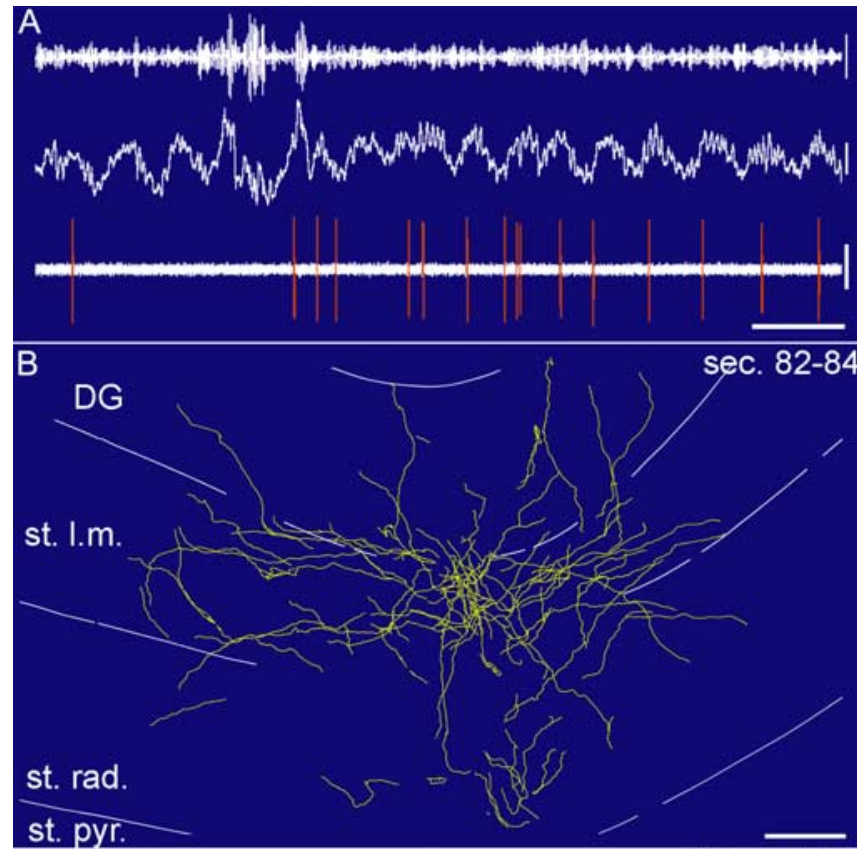

st. pyr.

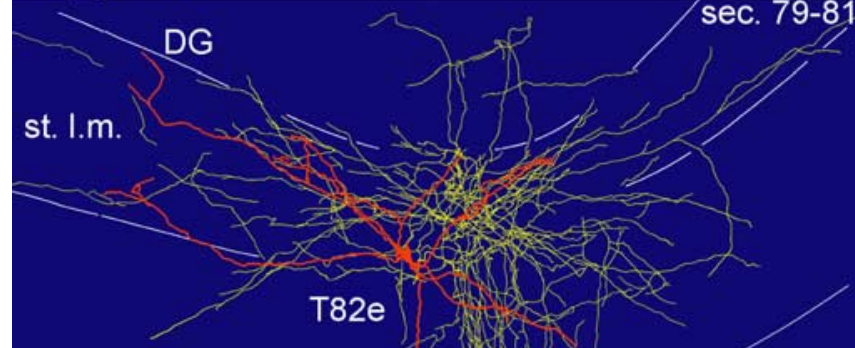

st. rad.

st. pyr.

st. or.

alveus

Neurobiotin

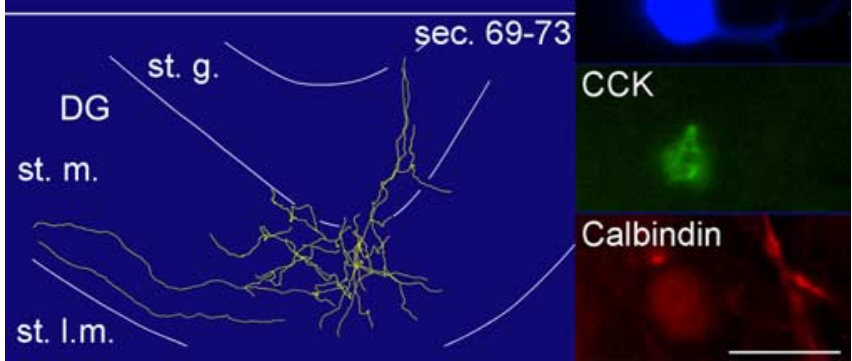

Figure 3. In vivo firing patterns and visualization of a CCK-expressing perforant-pathassociated cell (T82e). $\boldsymbol{A}$, In vivo firing patterns of the cell. Note that during the initial ripple episodes, the cell did not fire but became active during the subsequent theta oscillations, when it fired at the ascending phase of the theta waves recorded in the stratum pyramidale with a second electrode. Calibration: $0.2 \mathrm{~s}$; Ifp and spikes, $0.5 \mathrm{mV}$; ripples, $0.1 \mathrm{mV}$. B, Reconstruction of the soma and dendrites (orange) is shown complete; the axon (yellow) is shown from selected series of sections as indicated (bottom section number marks more caudal position). Scale bar (same for all 3 projections), $100 \mu \mathrm{m}$. C, Immunofluorescence micrograph of the neurobiotinlabeled cell (blue), CCK (green), and calbindin (red) immunoreactivity. Scale bar, $20 \mu \mathrm{m}$. st. rad., Stratum radiatum; st. pyr., stratum pyramidale; st. I.m., stratum lacunosum moleculare; DG, dentate gyrus; st. m., stratum moleculare; st. g., stratum granulosum; sec., section.

\section{Somato-dendritic and axonal distribution and postsynaptic} targets of CCK-expressing interneurons

Some processes of all nine CCK-expressing interneurons were reconstructed using a drawing tube. The somata and dendritic 
orientation of the cells were highly variable and showed no correlation to their axonal distribution. Two cells had cell bodies in stratum oriens, one basket cell with horizontally running dendrites (Fig. $1 \mathrm{~A}$ ), and the perforant-path-associated cell with radial dendrites (Fig. 4B). Three cells had soma in the pyramidal cell layer with radial dendrites; the other four cells had somata in the distal part of stratum radiatum, with dendrites mainly in the stratum radiatum but reaching into all layers to a different extent (Figs. $2 A, 3 B$ ).

The axonal branches of four cells (T64c, T147a, T152b, T165d) were concentrated in stratum pyramidale; thus, they corresponded to basket cells. Random samples of boutons from three of the cells ( $n=11,17,12$, respectively) (Table 2 ) were tested by electron microscopy to identify the postsynaptic targets and indicated that they were a homogeneous population $\left(p>0.6 ; \chi^{2}\right.$ test $)$. About one-half of the synapses targeted the somata of pyramidal cells (Figs. 1C, 5B; Table 2), and the other main targets were small- and medium-sized dendritic shafts of pyramidal cells, identifying them as basket cells. Many boutons of all CCK-expressing interneurons tended to embrace their postsynaptic targets (Fig. 5D) and/or often had finger-like invaginations into the boutons from postsynaptic dendrites or other axons (Fig. $5 B, C$ ), possibly maximizing the area of membrane contact. For one of the recorded CCK-expressing interneurons (T99d), only a very partial axon could be visualized because of weak filling. The radial dendritic pattern and the VIP expression of this cell (Acsady et al., 1996) suggested that it was a basket cell, but, because of the lack of efferent synaptic target information, we refer to it as unclassified.

The axons of two other CCKexpressing cells (T46d, T159a) were located mainly in stratum radiatum, similar to Schaffer collateral-associated cells, but some branches also innervated strata pyramidale and oriens (Fig. 2A). Interestingly, the axonal boutons in and around the pyramidal layer, including most of stratum radiatum, were lobulated and larger compared with their boutons at the radiatum/ lacunosum moleculare border. We characterized bouton size by the mean twodimensional projected area using light microscopy of Tritontreated sections. Boutons in stratum pyramidale and adjacent layers were $0.71 \pm 0.32$ and $0.61 \pm 0.29 \mu \mathrm{m}^{2}$ for cells T46d and T159a, respectively, which is the largest of any GABAergic cell encountered so far in the hippocampus. The boutons were distributed densely along the axon (Fig. 5A) and lobulated as a result of flattening along the postsynaptic dendrites, as determined by subsequent electron microscopy (Fig. 5D,E). These big boutons
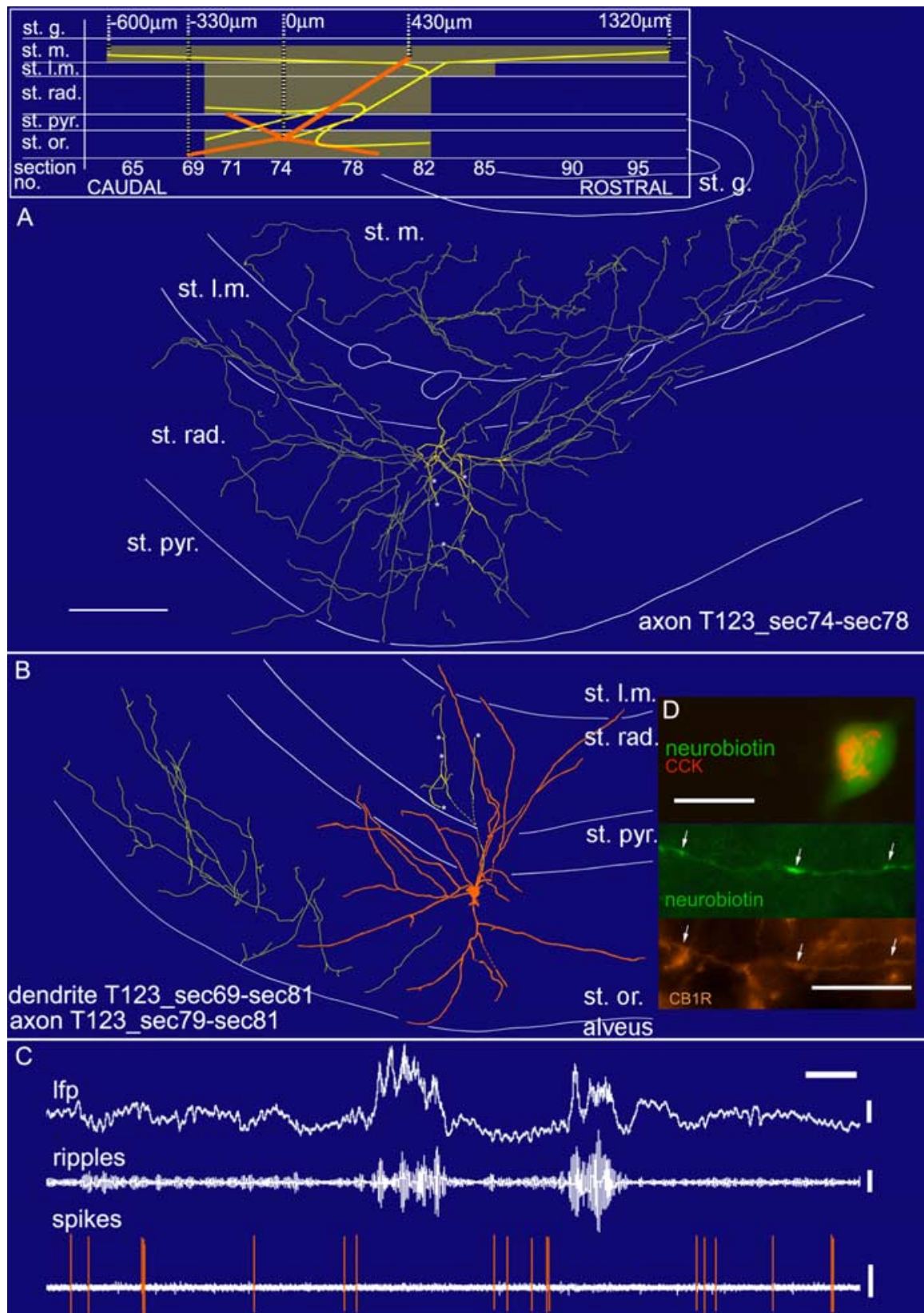

Figure 4. In vivo firing patterns and visualization of a CCK-expressing perforant-path-associated cell (T123b). $A, B$, Reconstruction of the soma and dendrites (orange) is shown complete; the axon (yellow) is shown from selected series of sections as indicated (bottom section number marks more caudal position). Asterisks mark the continuation of the main axon in $\boldsymbol{A}$ and $\boldsymbol{B}$. Scale bar, 100 $\mu \mathrm{m}$. Laminar boundaries are adjusted to reflect the position of processes as far as possible, but because of the tangential cutting plane, boundaries strongly shifted from section to section. A schematic sagittal view representing the cell shows rostrocaudal dimensions. C, In vivo firing pattern of the cell. Note the absence of firing during ripple episodes. Calibration: Ifp, $0.5 \mathrm{mV}, 0.2 \mathrm{~s}$; ripples, $0.1 \mathrm{mV}$; spikes, $0.5 \mathrm{mV}$. D, Immunofluorescence micrographs of the cell labeled by neurobiotin (green) showing CCK immunoreactivity (red) in the soma and immunoreactivity for the cannabinoid receptor (B1 (orange) in the axonal membrane. Immunopositive axons from unlabeled cells are also evident. Scale bars: top, $20 \mu \mathrm{m}$; bottom, $10 \mu \mathrm{m}$. st. rad., Stratum radiatum; st. pyr., stratum pyramidale; st. I.m., stratum lacunosum moleculare; st. m., stratum moleculare; st. g., stratum granulosum; st. or., stratum oriens; sec., section; no., number.

are different in both cells ( $p<0.0001$; Mann-Whitney $U$ test) from the smaller boutons in the distal radiatum/lacunosum moleculare zone, which were ordinary varicosities with twodimensional projected areas of $0.48 \pm 0.18$ and $0.36 \pm 0.15 \mu \mathrm{m}^{2}$ for cells T46d and T159a, respectively. The two cells were similar ( $p>0.4 ; \chi^{2}$ test) with respect to the identity of their postsynaptic targets in strata pyramidale and radiatum $(n=29,33)$, but their postsynaptic elements $(n=25,37)$ differed $\left(p<0.005 ; \chi^{2}\right.$ test $)$ 
Table 1. Molecular testing of in vivo recorded CCK-expressing interneurons by immunocytochemistry

\begin{tabular}{|c|c|c|c|c|c|c|c|c|c|}
\hline \multirow[b]{2}{*}{ Molecules tested } & \multicolumn{9}{|c|}{ CCK-immunopositive interneurons } \\
\hline & $\begin{array}{l}\text { T64c } \\
\text { (basket) }\end{array}$ & $\begin{array}{l}\text { T147a } \\
\text { (basket) }\end{array}$ & $\begin{array}{l}\text { T152b } \\
\text { (basket) }\end{array}$ & $\begin{array}{l}\text { T165d } \\
\text { (basket) }\end{array}$ & $\begin{array}{l}\text { T46d } \\
\text { (apical dendrite } \\
\text { innervating) }\end{array}$ & $\begin{array}{l}\text { T159a } \\
\text { (apical dendrite } \\
\text { innervating) }\end{array}$ & $\begin{array}{l}\text { T82e } \\
\text { (perforant path } \\
\text { associated) }\end{array}$ & $\begin{array}{l}\text { T123b } \\
\text { (perforant path } \\
\text { associated) }\end{array}$ & $\begin{array}{l}\text { T99d } \\
\text { (unclassified) }\end{array}$ \\
\hline CCK & + & + & + & + & + & + & + & + & + \\
\hline VIP & - & - & + & + & & - & - & & + \\
\hline SOM & & & & & & & & - & \\
\hline NPY & & - & & & & - & & - & \\
\hline CRF & & & & & & - & & & \\
\hline РPTВ & & + & & + & & - & & & \\
\hline VGLUT3 & & + & - & & & + & - & - & \\
\hline GAD & & + & + & & & + & + & + & \\
\hline Parvalbumin & - & - & - & - & & - & - & & - \\
\hline Calbindin & & - & - & & & - & + & - & \\
\hline Calretinin & & - & - & - & & - & - & & \\
\hline CB1 rec & & + & + & & & + & & + & \\
\hline mGluR1 $\alpha$ & - & - & weak + & - & - & - & - & - & \\
\hline Input mGluR7a & - & & & & & & & & \\
\hline Input mGluR8a & & & & & & & & - & \\
\hline $\mathrm{GABA}_{\mathrm{A}} \alpha 1$ & & - & - & - & & - & & - & \\
\hline NK1 rec & & & + & & & + & - & - & - \\
\hline NOS & & - & - & - & & - & & - & \\
\hline
\end{tabular}

Cells were tested by immunofluorescence for up to 15 molecules on soma, dendrites, and axonal boutons in separate sections or by rereacting the same section if the cell had been immunonegative. The input terminals of one cell were tested for mGluR7a and mGluR8a. +, Immunopositive; -, immunofluorescence undetectable in cell, but nearby cells show immunoreactivity; vacant positions, cell not tested. rec, Receptor; NK1, neurokinin-1; NOS, nitric oxide synthase.

Table 2. Postsynaptic targets as determined by electron microscopy from random samples of boutons

\begin{tabular}{|c|c|c|c|c|c|c|c|c|c|c|}
\hline \multirow[b]{3}{*}{ Cell } & \multirow[b]{3}{*}{ Type } & \multirow[b]{3}{*}{ Area } & \multirow{3}{*}{$\begin{array}{l}\text { Number of } \\
\text { synapses }\end{array}$} & \multicolumn{7}{|c|}{ Postsynaptic targets } \\
\hline & & & & \multicolumn{4}{|c|}{ Pyramidal cell } & \multirow[b]{2}{*}{ IN } & \multicolumn{2}{|c|}{ Granule cell } \\
\hline & & & & Soma & Dendrite & & Spine & & Dendrite & Spine \\
\hline & & & & & Apical & Small & & & & \\
\hline T64c & Basket & or., pyr., rad. & 11 & $64 \%$ & $9 \%$ & $27 \%$ & $0 \%$ & $0 \%$ & & \\
\hline T147a & Basket & or., pyr., rad. & 17 & $47 \%$ & $12 \%$ & $41 \%$ & $0 \%$ & $0 \%$ & & \\
\hline $\mathrm{T} 152 \mathrm{~b}$ & Basket & or., pyr., rad. & 12 & $50 \%$ & $8 \%$ & $42 \%$ & $0 \%$ & $0 \%$ & & \\
\hline \multirow[t]{3}{*}{ T46d } & ap.d.inn. & Total & 29 & $10 \%$ & $45 \%$ & $24 \%$ & $4 \%$ & $17 \%$ & & \\
\hline & & pyr., prx. rad. & 18 & $17 \%$ & $61 \%$ & $22 \%$ & $0 \%$ & $0 \%$ & & \\
\hline & & dist. rad. & 11 & $0 \%$ & $18 \%$ & $27 \%$ & $9 \%$ & $46 \%$ & & \\
\hline \multirow[t]{4}{*}{ T159a } & ap.d. inn. & Total & 42 & $7 \%$ & $26 \%$ & $57 \%$ & $0 \%$ & $10 \%$ & & \\
\hline & & pyr., prx. rad. & 19 & $16 \%$ & $42 \%$ & $37 \%$ & $0 \%$ & $5 \%$ & & \\
\hline & & dist. rad. & 14 & $0 \%$ & $21 \%$ & $64 \%$ & $0 \%$ & $14 \%$ & & \\
\hline & & or. & 9 & $0 \%$ & $0 \%$ & $89 \%$ & $0 \%$ & $11 \%$ & & \\
\hline \multirow[t]{4}{*}{ T82e } & Perf.p.as. & Total & 38 & $0 \%$ & $3 \%$ & $55 \%$ & $5 \%$ & $11 \%$ & $21 \%$ & $5 \%$ \\
\hline & & rad. & 10 & $0 \%$ & $10 \%$ & $80 \%$ & $0 \%$ & $10 \%$ & & \\
\hline & & lac-mol. & 17 & $0 \%$ & $0 \%$ & $76 \%$ & $12 \%$ & $12 \%$ & & \\
\hline & & dentate gyr. & 11 & & & & & $9 \%$ & $73 \%$ & $18 \%$ \\
\hline \multirow[t]{4}{*}{$\mathrm{T} 123 \mathrm{~b}$} & Perf.p.as. & Total & 36 & $0 \%$ & $14 \%$ & $80 \%$ & $0 \%$ & $6 \%$ & & \\
\hline & & or. & 10 & $0 \%$ & $0 \%$ & $100 \%$ & $0 \%$ & $0 \%$ & & \\
\hline & & rad. & 12 & $0 \%$ & $25 \%$ & $75 \%$ & $0 \%$ & $0 \%$ & & \\
\hline & & lac-mol. & 14 & $0 \%$ & $14 \%$ & $72 \%$ & $0 \%$ & $14 \%$ & & \\
\hline
\end{tabular}

Main targets are in boldface. IN, Interneuron; ap.d. inn., apical dendrite-innervating cell; Perf.p.as., perforant-path-associated cell; or., stratum oriens; pyr., stratum pyramidale; rad., stratum radiatum; prx. and dist. rad., proximal and distal stratum radiatum; lac-mol., stratum lacunosum moleculare; dentate gyr., dentate gyrus.

in the distal versus proximal stratum radiatum (Table 2). The random sampling of boutons showed that the main targets in stratum pyramidale and proximal radiatum were the shafts of large apical dendrites of pyramidal cells; hence, we named these cells apical dendrite-innervating neurons. Only one interneuron dendrite was found as a target in the proximal stratum radiatum sample. In contrast, about one-third of the targets were dendrites of interneurons in the distal stratum radiatum. Such an asym- metrical innervation profile suggests a cell-type-specific selection of the postsynaptic targets and indicates that the cell made synapses preferentially onto interneurons with dendrites at the radiatum/lacunosum moleculare border, an area rich in CCKexpressing cells. Of all boutons sampled for these cells $(n=71)$, $\sim 9 \%$ (T46d, 10\%; T159a, 7\%) made synapses onto somata of pyramidal cells, a proportion clearly different $(p<0.005$; Fisher's exact test) from the basket cells, which had $47-64 \%$ somata 
among their synaptic targets $(n=40)$. In addition, examining the synaptic targets of the apical dendrite-targeting cells together with those of the basket cells described above resulted in a heterogeneous population $\left(p<0.001 ; \chi^{2}\right.$ test), with a post hoc test indicating T46d and T159a as different. These results define the apical dendrite-innervating cell as one variety of CCK-expressing interneuron.

The axonal branches (Figs. $3 B, 4 A, B$ ) of the remaining two CCK-expressing cells (T82e, T123b) were concentrated in stratum lacunosum moleculare with many branches crossing the fissure into the molecular layer and even granule cell layer (T82e) of the dentate gyrus, similar to perforant-path-associated cells (Hájos and Mody, 1997; Vida et al., 1998), but additional branches also strongly innervated stratum radiatum. One of the cells (T123b) also had a number of branches in stratum oriens; this cell was at the border between the CA1 area and the subiculum. Electron microscopic analysis showed that these two cells $(n=38,36)$ were similar in terms of the identity $\left(p>0.1 ; \chi^{2}\right.$ test $)$ and diameter $(p>0.8$; Mann-Whitney test) of their synaptic targets in the CA1 area. Small- and medium-sized dendritic shafts of pyramidal and granule cells were the main postsynaptic elements (pooled median diameter in the CA1 area, $0.56 \mu \mathrm{m}$; interquartile range, $0.45-0.68 \mu \mathrm{m} ; n=$ $63)$, in contrast to the apical dendritetargeting cells T46d and T159a (pooled median diameter, $1.35 \mu \mathrm{m}$; interquartile range, $0.49-1.58 \mu \mathrm{m} ; n=65)$, which targeted significantly thicker dendrites $(p<$ 0.005; Mann-Whitney test). Interneurons, dendritic spines of pyramidal and granule cells, and dendritic shafts of apical dendrites of pyramidal cells were also targeted to a lesser extent by perforant-pathassociated cells (Table 2).

\section{Firing of CCK-expressing interneurons during theta and ripple oscillations}

To evaluate the firing patterns of CCK-expressing interneurons, recordings were compared from three different brain states: theta oscillations, non-theta/nonsharp wave periods, and sharp waveassociated ripple episodes (Csicsvari et al., 1999; Klausberger et al., 2003, 2004). The discharge frequencies for all individual cells during the three brain states are listed in Table 3. All cells discharged with highest frequency during theta oscillations. On average, the nine CCK-expressing interneurons fired with $8.8 \pm 3.3$ $\mathrm{Hz}$ during theta oscillations, which is significantly higher $(p<$ 0.005; Wilcoxon rank test) than their firing during non-theta/ non-sharp wave periods at $1.2 \pm 1.4 \mathrm{~Hz}$. During ripple episodes, the firing at $1.7 \pm 2.0 \mathrm{~Hz}$ was not significantly different $(p>0.1$; Wilcoxon rank test) from the firing during non-theta/non-sharp wave periods.

During theta oscillations, CCK-expressing interneurons ( $n=$
9) fired preferentially at the ascending phase of the theta oscillations recorded extracellularly in the pyramidal cell layer (Fig. $6 A)$, on average, at $155 \pm 81^{\circ}$ [mean theta phase \pm angular deviation; Batschelet method (Zar, 1999); 0 and $360^{\circ}$ mark the trough]. This is significantly different $(p<0.0005$; WatsonWilliams test) from eight PV-expressing basket cells [five of them have been published by Klausberger et al. (2003)], which fire at a mean theta angle of $234 \pm 92^{\circ}$ (Fig. 6A). Two CCK-expressing basket cells (T64c, T165d) had a weak double-peaked distribution in the theta histogram, but no difference could be detected in the mean firing phase of basket $(n=4)$ versus dendriteinnervating $(n=5)$ CCK-expressing interneurons $(p>0.1$; Watson-Williams test). The mean theta phase of each labeled cell is given in Table 3. Interestingly, some CCK-expressing interneurons showed spike accommodation during bursts of action potentials within a theta cycle (Fig. $1 D$ ), as it would be expected for regular-spiking neurons.

Because the soma of a single CA1 pyramidal cell receives 

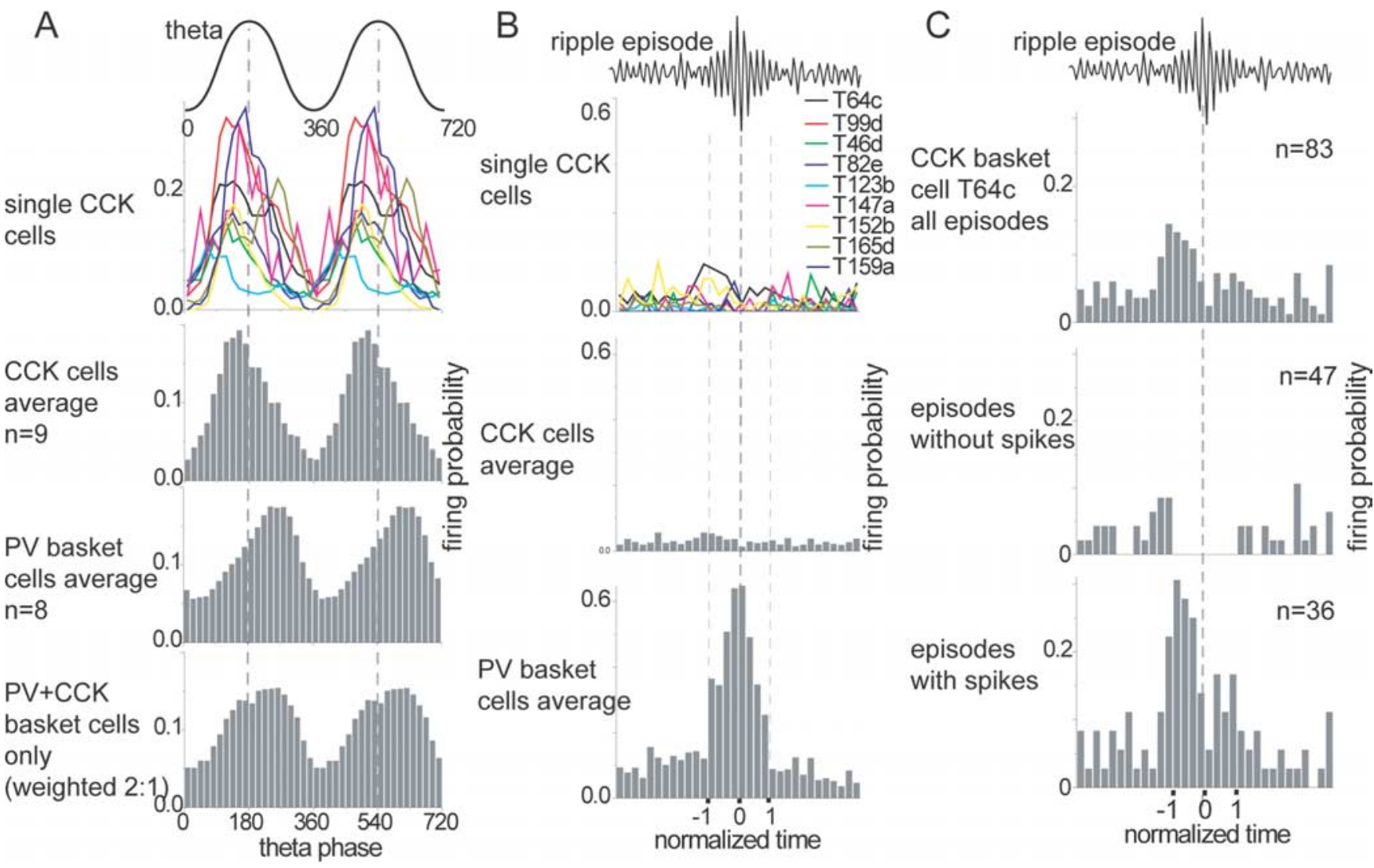

Figure 6. CCK-expressing interneurons exhibit distinct firing patterns during theta and ripple oscillations. A, During theta oscillations, CCK-expressing interneurons (color traces of individual cells) fire with highest probability at the ascending phase of the theta wave recorded extracellularly in stratum pyramidale. For each cell, $1352 \pm 1121$ (range, 42-3693) theta cycles were recorded. For clarity, two theta cycles are shown. Top, Schematic theta wave; 0,360 , and $720^{\circ}$ mark the troughs. The averaged firing probability of the CCK-expressing interneurons and, for comparison, of eight PV-expressing basket cells [5 published by Klausberger et al. (2003)] is shown in gray columns. Note that CCK-expressing cells fire out of phase with PV-expressing basket cells. Because the somata of pyramidal cells receive input from PV- and CCK-expressing basket cells at a probable ratio of 2:1 (Nyiri et al., 2001), the average firing probability of the PV-expressing basket cells was multiplied by 0.66 and added to the average firing probability of the three identified CCK-expressing basket cells multiplied by 0.33 . The weighted sum of the firing probabilities of CCK- and PV-expressing basket cells still provides a theta-modulated GABAergic input to the soma of pyramidal cells. $B$, During ripple episodes, the average firing probability of the CCK-expressing interneurons showed no change (gray columns) relative to the preripple and postripple time. In contrast, the PV-expressing basket cells strongly increased their firing. Individual CCK-expressing interneurons (color traces) exhibited variable firing patterns ranging from slightly excited at the beginning and end of the ripple episodes to weakly inhibited. For each cell, $55 \pm 36$ (range, $18-113$ ) ripple episodes were recorded. The start, maximum amplitude, and end (bottom) of the normalized ripple episodes are marked as $-1,0$, and 1, respectively. C, Comparison of ripple episodes with and without the firing of basket cell T64c. The peri-ripple periods preceding or after ripples with (bottom) or without (middle) basket-cell firing show similar firing rates, indicating that the instantaneous firing frequency of the cell did not influence whether it would fire during a certain ripple episode.

GABAergic input from both PV- and CCK-expressing basket cells, we have estimated the summed effect of these neurons (Fig. $6 \mathrm{~A}$, bottom histogram). First, we calculated the mean firing histogram of the four CCK-expressing basket cells, multiplied it by 0.33 , and added it to the mean firing histogram of the PV basket cells multiplied by 0.66 , because the ratio of PV- and CCKexpressing boutons on pyramidal cell somata was estimated to be 2:1 (Nyiri et al., 2001). Although the mean theta phase between CCK and PV basket cells differed by $113^{\circ}$, the weighted sum of their histograms indicates a clear minimum of firing at and just after the trough of the theta oscillations, at a time when, on average, pyramidal cells are most active. This estimation assumes similar number of release sites of CCK- and PV-expressing boutons, similar release probability, and time course of release and does not take into account the potential effect of different $\mathrm{GABA}_{\mathrm{A}}$ receptor subtypes postsynaptic to PV- or CCK-expressing basket cells (Thomson et al., 2000; Nyiri et al., 2001; Klausberger et al., 2002). The overall GABAergic modulation of pyramidal cell activity would also involve contributions of IPSPs from dendrites and the axon initial segment.

During sharp wave-associated ripple episodes, the average of all CCK-expressing interneurons did not show any correlation to the ripple episode, in contrast to PV-expressing cell types, which all strongly changed their firing activity (Fig. 6B). None of the individual CCK-expressing interneurons showed a strong change of activity during the ripple episodes; one cell exhibited a weak increase at the beginning and end of the ripples (T64c), whereas some others showed an overall weak decrease of firing (T123b, T165d). Such a weak correlation between firing and ripple episodes could be interpreted as a lack of synaptic input from circuits contributing to ripple oscillations. However, a closer inspection of single ripple events indicated that CCK cells show ripplerelated firing. For example, basket cell T64c appeared to be specifically silenced during some ripple episodes (Fig. $1 G$ ) but was activated at the beginning and end of other ripple episodes (Figs. $1 F, 6 C)$, indicating a sophisticated balance between incoming excitation and inhibition in this neuron, rather than a lack of sharp wave-related inputs. In addition, a specific inhibition on some ripple oscillations could also be seen during the labeling protocol, even when the cell was excited by positive current (Fig. $1 \mathrm{H})$. To quantify the activation of this cell during ripples, we calculated the mean firing rate plus $3 \times \mathrm{SD}$ outside the ripple 
episode (first eight and last eight bins) (Fig. 6C, top histogram). Within the summed ripple episodes (between -1 and 1) (Fig. $6 C$ ), three consecutive bins have values above the mean $+3 \times \mathrm{SD}$, which is regarded as a specific activation because this never occurred in 1000 shuffled ripple histograms. These were generated by shuffling all ripple episode time windows of this cell over the spike train during non-theta/non-sharp wave episodes and summing them. To test whether the silencing of the cell during some ripple episodes (Fig. $1 G$ ) is different from random, we calculated that during $32 \%$ of the 83 recorded ripple episodes, the cell did not fire (Fig. $6 \mathrm{C}$, bins between -1 and 1) but fired before and after the episode (Fig. 6C, first and last 12 bins in the histogram). This proportion of ripple episodes is different from random, because it occurred only in 31 of 1000 shuffled, randomly created ripple histograms $(3.1 \% ; p<0.05)$ described above. The discharge frequency of this cell during individual ripple episodes showed that during $57 \%$ of the episodes (including episodes without firing in the 24 bins bordering the ripple) (Fig. $6 C$ ), the cell was silent (Fig. $6 C$, middle), and during the rest, the cell fired one to four spikes (Fig. 6C, bottom). We tested whether the presence or absence of firing during ripples resulted from an overall difference in instantaneous firing outside the ripple episode (five bins immediately before and five bins directly after the ripple), but there was no difference ( $p>0.3$; Mann-Whitney test) in the firing rate before and after the ripple episodes with $(n=36)$ or without $(n=47)$ firing during the ripples (Fig. $6 C$ ). In addition, the peak amplitude of the ripples between the two populations of ripples was not different either ( $p>0.5$; Mann-Whitney test), and no obvious difference could be seen in the local field potential before the ripple episodes, tested with power spectra or averaging the local field potential of the two populations of ripple episodes (data not shown). These data indicate that neither the general state of the network, which is reflected in the local field potential, nor the instantaneous firing rate of the CCKexpressing interneuron influenced their probability of firing during a given ripple episode. Therefore, the firing of the CCK cell during ripple episodes is regulated most likely by the specific microcircuit innervating the cell and results in an episodedependent suppression or activation of firing. The firing of nine CCK-expressing interneurons during $12 \pm 14 \%$ of ripple episodes is different ( $p<0.001$; Mann-Whitney $U$ test) from their firing during theta oscillations, when they discharge during $89 \pm$ $9 \%$ of theta cycles. In addition, PV-expressing basket cells $(n=7)$ exhibit a much more stereotyped firing pattern during ripple oscillations and fire, on average, during $90 \pm 6 \%$ of the ripple episodes, which is also significantly different from the firing of CCK-expressing interneurons during ripples ( $p<0.005$; MannWhitney $U$ test).

\section{Firing patterns of interneurons in drug-free animals in comparison with CCK-expressing interneurons in anesthetized rats}

To test whether interneurons with firing patterns similar to those of CCK-expressing cells exist in the hippocampal CA1 area of nonanesthetized rats, we recorded the firing patterns of 99 putative interneurons, as defined previously (Csicsvari et al., 1999), during theta oscillations in awake animals and during ripple episodes in sleeping animals. Cells with a mean theta phase between 60 and $180^{\circ}(n=13)$ were further analyzed. Of these, seven units were excluded, which had a biphasic ripple histogram and probably correspond to axo-axonic cells. This prediction is based on similar ripple histograms obtained for two published (Klausberger et al., 2003) and two newly recorded and identified axo-
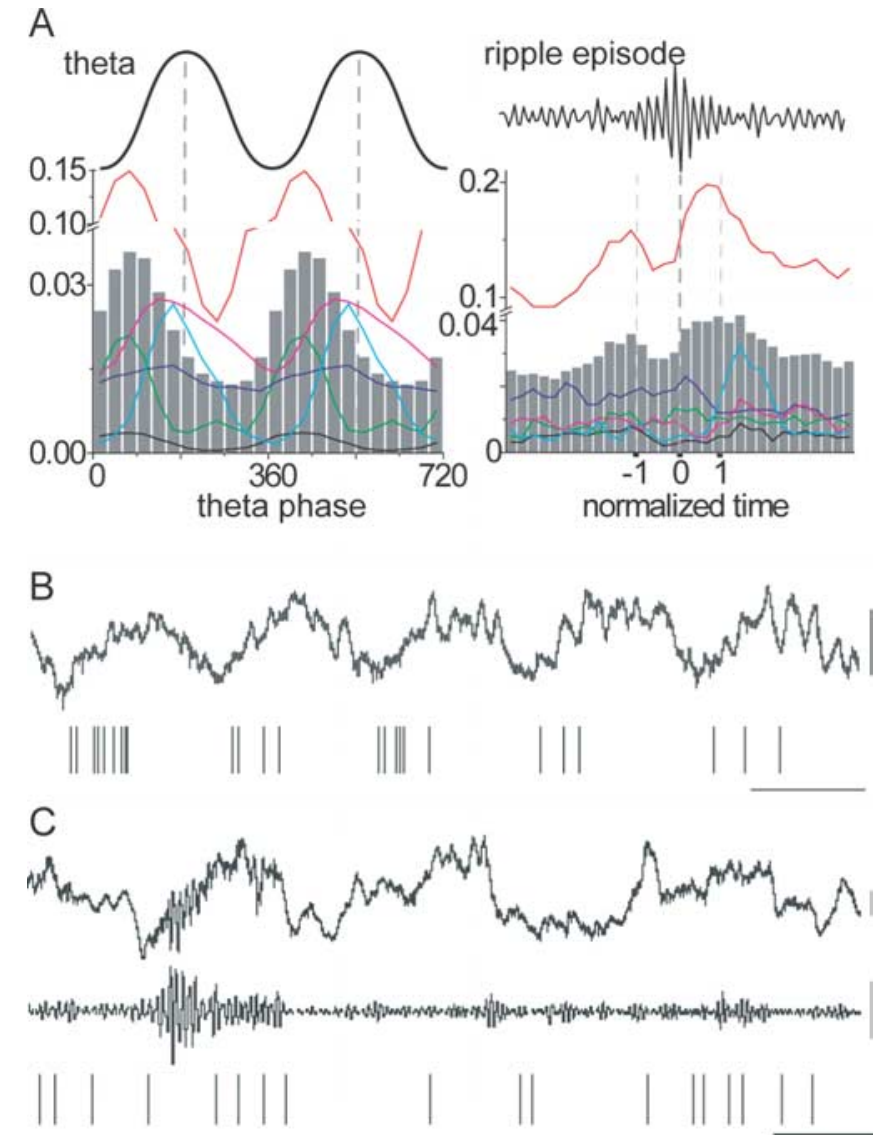

Figure 7. A subset of interneurons in drug-free and behaving animals show comparable firing patterns to CCK-expressing interneurons in anesthetized rats. $A$, The firing probability of six cells (color traces) is shown during theta oscillation and ripple oscillations; the mean is shown as gray columns. Theta oscillations were recorded while the animal was exploring an environment; ripples were recorded in slow-wave sleep. Note that none of these cells, selected by theta firing phase alone, exhibited a strong increase or inhibition of firing probability during ripple episodes like PV-expressing cells. One cell (red, top) showed a weak increase in firing at the beginning and end of the ripple episode, another (light blue) increased its firing slightly after the ripples, and the other four cells showed no change of firing during and around the ripple events. $\boldsymbol{B}, \boldsymbol{C}$, Firing sequences of an interneuron (red trace in $\boldsymbol{A}$ ) during theta $(\boldsymbol{B})$ and ripple $(C)$ oscillations recorded by a tetrode in the pyramidal layer. The cell fired at the ascending phase of the theta cycle and at the beginning and end of the ripple episode. Calibration: $0.1 \mathrm{~s}, 0.2 \mathrm{mV}$.

axonic cells. These axo-axonic cells in anesthetized animals fired around the positive peak of the theta oscillations at $182 \pm 58^{\circ}$ $(n=4)$. The firing patterns of all six remaining cells are shown in Figure 7A. Interestingly, none of these six cells, selected on the basis of their spike timing during theta oscillations, showed a strong increase in firing during ripple episodes like PVexpressing basket and bistratified cells or a specific depression like O-LM cells (Klausberger et al., 2003, 2004). This indicates that these six cells were not just outliers of PV-expressing cell types but represent (a) separate class(es) of cells. The small number of such cells may be explained by the expected lower number of CCK- compared with PV-expressing basket cells and, more importantly, by our restriction of recording in the nonanesthetized rats to the stratum oriens and pyramidale, where CCKexpressing interneurons are relatively rare (Pawelzik et al., 2002).

\section{Discussion}

We have shown that separate sets of CCK- or PV-expressing GABAergic cells, innervating similar subcellular domains of pyramidal cells, contribute differentially to hippocampal network 
oscillations through distinct spike timing in vivo. There are interneurons with firing patterns similar to identified CCK interneurons in behaving animals, confirming the existence of multiple interneuron classes with distinct firing patterns under drug-free conditions.

\section{Molecular and synaptic target diversity of CCK interneurons} Some CCK cells are basket cells (Harris et al., 1985; Nunzi et al., 1985), innervating somata and proximal dendrites, similar to PVexpressing basket cells. Other CCK cells (Cope et al., 2002; Pawelzik et al., 2002) make synapses mainly either on large apical or small- and medium-sized dendrites. The apical dendriteinnervating cells mainly terminate in stratum radiatum and oriens, similar to PV-expressing bistratified cells, whereas perforant-path-associated cell axons are biased to stratum lacunosum moleculare, like those of O-LM cells. However, dendriteinnervating CCK-expressing interneurons have wider axonal arbors, and the perforant-path-associated cells also innervate other layers. Surprising axonal projections were found from CA1 CCKexpressing perforant-path-associated cells to the dentate molecular layer. This GABAergic projection needs additional investigation in view of entorhino-hippocampal interactions (Steffenach et al., 2005). The low probability of labeling CCK interneurons in vivo and their large number of signaling molecules allow only a few conclusions about molecular expression profiles. Together with previous studies, it appears that VIP and VGLUT3 are expressed by separate types of CCK cells (Somogyi et al., 2004), and basket cells also express PPTB (for neocortex, see Kaneko et al., 1998). Calbindin is expressed by some dendrite-innervating CCK cells (Cope et al., 2002), and we found CB1 receptors in the axons of all tested CCK basket- (Katona et al., 1999) and dendriteinnervating cells. The extended membrane apposition via invaginating postsynaptic fingers into CCK boutons, and the highly flattened boutons over the postsynaptic targets might help to maximize and restrict locally the activation of presynaptic $\mathrm{CB} 1$ receptors.

\section{Episode-dependent firing of CCK cells during ripple oscillations}

The firing of CCK-expressing interneurons, on average, shows no correlation to ripple episodes. This is surprising, considering that the majority of CCK-expressing interneurons is located in stratum radiatum, receiving massive excitatory input from the CA3 area during sharp waves (Csicsvari et al., 2000). However, during single ripple episodes, the same CCK cell appears to be sometimes specifically silenced and sometimes excited. Such an episodedependent firing pattern is different from the stereotyped firing of all other interneurons reported so far (Klausberger et al., 2003, 2004) and might reflect a subtle balance of incoming excitation and inhibition. The participation of CCK cells in certain ripples may be influenced by the recent history of the network, as shown for pyramidal cells. Therefore, CCK-expressing interneurons might specifically contribute to selecting which pyramidal cells are active in a certain ripple episode as part of a cell assembly. Their participation may be driven by activity-dependent changes in their glutamatergic and/or inhibitory inputs (Lamsa et al., 2005).

Unlike the four types of PV-expressing cells, no clear differences were apparent in the firing patterns between CCKexpressing basket and dendrite-innervating interneurons. But the episode-dependent firing of CCK-expressing interneurons during ripple oscillations raises the possibility that during a certain ripple episode, CCK-expressing basket cells might be active while dendrite-innervating cells of the same pyramidal cell are silent, or vice versa. Such spatio-temporally regulated activity would independently regulate the input and output of pyramidal cells in an episode-dependent manner and could be observed if several identified CCK-expressing interneurons were recorded simultaneously. Alternatively, differences in the firing patterns might emerge only during more subtle behavioral conditions.

\section{Spike timing of CCK-expressing interneurons might contribute to sparse coding by place cells}

During theta oscillations, the majority of pyramidal cells discharge with $<0.1 \mathrm{~Hz}$ (Henze et al., 2000), but when a rat enters into the place field of a pyramidal cell, the neuron increases the firing up to $20 \mathrm{~Hz}$ (O'Keefe, 1976; O'Keefe and Recce, 1993; Wilson and McNaughton, 1993). Such a contrast in firing rate could be explained by a precise placement of glutamatergic inputs and synaptic weights, but inhibitory mechanisms might also contribute. A form of short-term plasticity, called depolarizationinduced suppression of inhibition (DSI) (Llano et al., 1991; Pitler and Alger, 1992), is mediated by endocannabinoids acting on $\mathrm{CB} 1$ receptors and results in a suppression of GABA release from CCK-expressing terminals (Katona et al., 1999; Ohno-Shosaku et al., 2001; Wilson and Nicoll, 2001; Losonczy et al., 2004). This downregulation of inhibition could take place during theta oscillations, because the prolonged activity of place cells might result in endocannabinoid release (Freund et al., 2003). When a rat enters into the place field of a given place cell, the neuron starts to fire just before the peak of the theta oscillations (O'Keefe and Recce, 1993), often with a complex spike burst (Harris et al., 2001), coincidentally with the CCK-expressing interneurons as shown in this study (Fig. 8) and axo-axonic cells (Klausberger et al., 2003). Therefore, the glutamatergic excitation of place cells at the initiation of firing overcomes the concerted somato-dendritic inhibition by CCK-expressing cells and the axon-initial-segment inhibition by axo-axonic cells. Axo-axonic cell firing and $\mathrm{GABA}_{\mathrm{A}}$ receptor activation on the axon initial segment may facilitate dendritic spike generation leading to complex spike bursts (Chen et al., 1997) and dendritic $\mathrm{Ca}^{2+}$ influx. This might result in the production of endocannabinoids and induction of DSI (Llano et al., 1991; Pitler and Alger, 1992) specifically in the CCK terminals innervating the active place cell, as a result of the spatially restricted action of endocannabinoids (Carlson et al., 2002; Chevaleyre and Castillo, 2004). The formation of endocannabinoids may also be facilitated by muscarinic acetylcholine receptors (Martin and Alger, 1999) and metabotropic glutamate receptors (Maejima et al., 2001), known to be activated during theta oscillations. Under such enhanced conditions, even a single burst of action potentials may lead to DSI (Pitler and Alger, 1992). During the following theta cycles, the CCK-expressing interneurons continue to release GABA only to the majority of the silent pyramidal cells, but not to the active place cell, increasing the firing probability of the latter on consecutive theta cycles (Fig. 8). Therefore, the selective suppression of inhibition by CCK-expressing interneurons could contribute to the sparse coding by pyramidal place cells. The inhibition mediated by PV-expressing basket cells is not lifted from the place cells and contributes to their theta modulation. Because of the average $180^{\circ}$ phase precession effect (Skaggs et al., 1996), place cell firing will mainly overlap with PVexpressing basket cell firing when place cell spiking is declining, and they stop firing (Fig. 8) at a phase when axo-axonic cell firing is increasing again (Klausberger et al., 2003). It remains to be seen whether endocannabinoids act fast enough to lift inhibition from the place cells, but perhaps increasing glutamatergic excitation in 


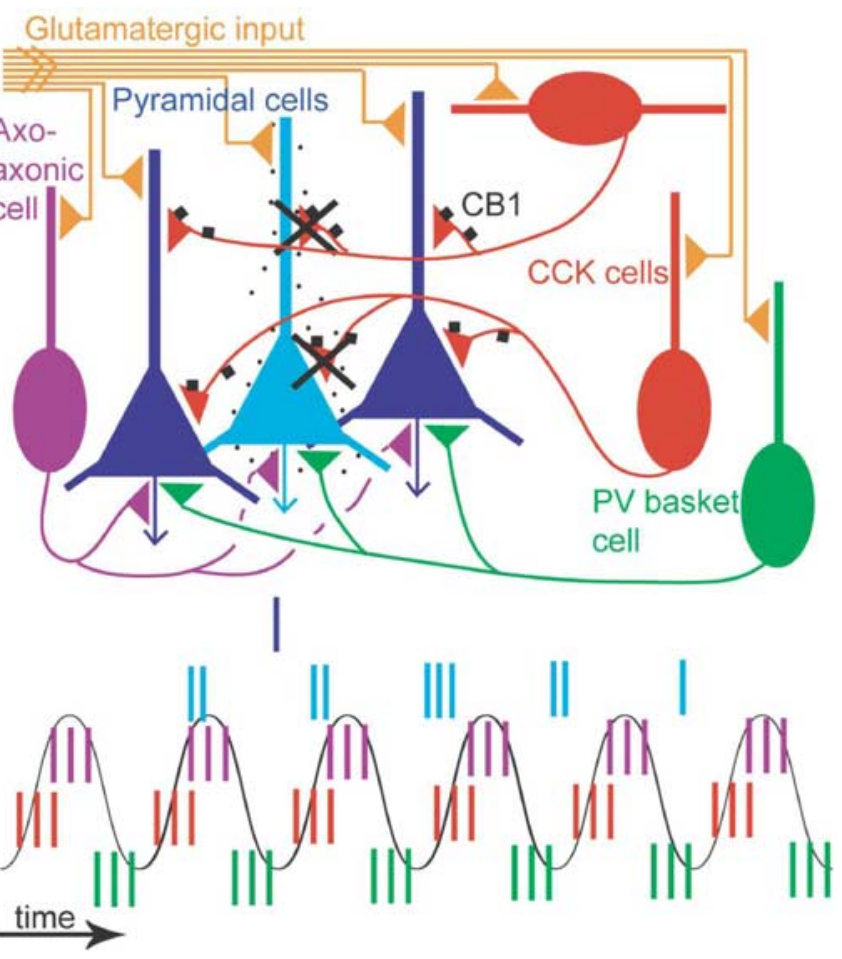

Figure 8. Hypothetical contribution of CCK-expressing interneurons to sparse coding by CA1 pyramidal cells during theta oscillations. The majority of pyramidal cells (dark blue) are silent as the animal explores a given place, whereas place cell (light blue) firing is theta modulated (spikes, vertical lines over a schematic theta wave). As the rat enters the place field of a pyramidal cell, the neuron starts to fire before the peak of the theta wave. The cell fires at gradually earlier phases during consecutive theta cycles. It is assumed that all pyramidal cells receive GABAergic input from PV-expressing basket cells (green), axo-axonic cells (purple), and several types of CCK-expressing cell (red). The PV basket cells fire, on average, before the place cells fire. The CCK-expressing interneurons fire, on average, at the ascending theta phase, at the same time when place cells start to fire. Thus, the glutamatergic excitation of place cells (yellow) must overcome the peak of inhibition by CCK-expressing and axo-axonic cells for the cell to start firing as the animal enters the place field. Only CCK-expressing cells have CB1 receptors on their presynaptic boutons (black squares), and when activated, these suppress GABA release. Place cells often fire complex spikes early in the place field leading to strong calcium influx, which in cooperation with muscarinic acetylcholine receptor activation would lead to the formation of endocannabinoids and a reduction of GABA release from only those CCK terminals that innervate the place cell. The CCK-expressing interneurons will fire and continue to release GABA to the majority of pyramidal cells, which are silent, keeping a high threshold for activation. In contrast, the place cell continues to fire with high frequency as a result of decreased inhibition and increasing excitation. Thus, the specific spike timing of CCK-expressing interneurons during theta oscillations and the expression of cannabinoid receptors on their terminals contribute to increasing the difference in firing between activated and nonactivated pyramidal cells.

the dendrites and intracellular $\mathrm{Ca}^{2+}$ release may lead to $\mathrm{CB} 1$ activation on the CCK terminals even before the place cells start to fire. The hypothesis also assumes that the spike timing of CCK cells is not dependent on the location of the animal and endocannabinoids modulate transmitter release during theta oscillations. This could only be tested by the local application of CB1 antagonist in the CA1 area during the recording of place cells in freely moving animals.

Distinct glutamatergic and/or GABAergic inputs could explain the different spike timing of CCK- and PV-expressing interneurons during theta oscillations. Some distinct GABAergic inputs to CCK-expressing interneurons could derive from neurons of the medial septum, which have at least two different phase relationships to theta oscillations in the CA1 area of the hippocampus (Borhegyi et al., 2004). Another GABAergic input specific to the CCK-expressing cells could derive from interneuron- specific interneurons (Gulyas et al., 1996) demonstrated to innervate CCK-expressing cells. Unfortunately, the in vivo spike timing of the interneuron-specific cells remains unknown.

\section{Complementary networks of PV- or CCK-expressing interneurons in the cerebral cortex}

A differential contribution of interneurons to network activity was reported also in the developing visual cortex (Fagiolini et al., 2004). Activation of $\alpha 1$ subunit containing $\mathrm{GABA}_{\mathrm{A}}$ receptors, which include the pools postsynaptic to PV-expressing basket cells on pyramidal cells (Klausberger et al., 2002), determine the onset of the critical period for ocular dominance plasticity. Input to $\alpha 2$ subunit-containing receptors, which include the pools to CCK-expressing basket cells (Nyiri et al., 2001), separately regulate the firing of pyramidal cells coding for visual input. Furthermore, $\alpha 1$ subunit-containing $\mathrm{GABA}_{\mathrm{A}}$ receptors mediate the sedative and amnesic effects of diazepam, whereas $\alpha 2$ subunitcontaining receptors underlie the anxiolytic effects of benzodiazepines (Rudolph and Mohler, 2004). Interneurons expressing CCK might be also influenced by specific subcortical pathways (Freund, 2003). Together with our results, the timing of CCK interneuron firing during ripple and theta oscillations might indicate a role in shaping the activity of subgroups and assemblies of pyramidal cells, in contrast to PV-expressing interneurons, which appear to provide more stereotyped oscillatory entrainment to the entire network.

\section{References}

Acsady L, Arabadzisz D, Freund TF (1996) Correlated morphological and neurochemical features identify different subsets of vasoactive intestinal polypeptide-immunoreactive interneurons in rat hippocampus. Neuroscience 73:299-315.

Borhegyi Z, Varga V, Szilagyi N, Fabo D, Freund TF (2004) Phase segregation of medial septal GABAergic neurons during hippocampal theta activity. J Neurosci 24:8470-8479.

Buzsaki G, Draguhn A (2004) Neuronal oscillations in cortical networks. Science 304:1926-1929.

Buzsaki G, Leung L-W, Vanderwolf CH (1983) Cellular bases of hippocampal EEG in the behaving rat. Brain Res Brain Res Rev 6:139-171.

Carlson G, Wang Y, Alger BE (2002) Endocannabinoids facilitate the induction of LTP in the hippocampus. Nat Neurosci 5:723-724.

Chen WR, Midtgaard J, Shepherd GM (1997) Forward and backward propagation of dendritic impulses and their synaptic control in mitral cells. Science 278:463-467.

Chevaleyre V, Castillo PE (2004) Endocannabinoid-mediated metaplasticity in the hippocampus. Neuron 43:871-881.

Cope DW, Maccaferri G, Márton LF, Roberts JDB, Cobden PM, Somogyi P (2002) Cholecystokinin-immunopositive basket and Schaffer collateralassociated interneurones target different domains of pyramidal cells in the CA1 area of the rat hippocampus. Neuroscience 109:63-80.

Csicsvari J, Hirase H, Czurko A, Mamiya A, Buzsaki G (1999) Oscillatory coupling of hippocampal pyramidal cells and interneurons in the behaving rat. J Neurosci 19:274-287.

Csicsvari J, Hirase H, Mamiya A, Buzsaki G (2000) Ensemble patterns of hippocampal CA3-CA1 neurons during sharp wave-associated population events. Neuron 28:585-594.

Fagiolini M, Fritschy JM, Low K, Mohler H, Rudolph U, Hensch TK (2004) Specific GABAA circuits for visual cortical plasticity. Science 303:1681-1683.

Ferraguti F, Cobden P, Pollard M, Cope D, Shigemoto R, Watanabe M, Somogyi P (2004) Immunolocalization of metabotropic glutamate receptor $1 \alpha(\operatorname{mGluR} 1 \alpha)$ in distinct classes of interneuron in the CA1 region of the rat hippocampus. Hippocampus 14:193-215.

Freund TF (2003) Interneuron diversity series: rhythm and mood in perisomatic inhibition. Trends Neurosci 26:489-495.

Freund TF, Katona I, Piomelli D (2003) Role of endogenous cannabinoids in synaptic signaling. Physiol Rev 83:1017-1066.

Grastyan E, Lissak K, Madarasz I, Donhoffer H (1959) Hippocampal elec- 
trical activity during the development of conditioned reflexes. Electroencephalogr Clin Neurophysiol Suppl 11:409-430.

Gulyas AI, Hájos N, Freund TF (1996) Interneurons containing calretinin are specialized to control other interneurons in the rat hippocampus. J Neurosci 16:3397-3411.

Hájos N, Mody I (1997) Synaptic communication among hippocampal interneurons: properties of spontaneous IPSCs in morphologically identified cells. J Neurosci 17:8427-8442.

Harris KD, Hirase H, Leinekugel X, Henze DA, Buzsaki G (2001) Temporal interaction between single spikes and complex spike bursts in hippocampal pyramidal cells. Neuron 32:141-149.

Harris KM, Marshall PE, Landis DMD (1985) Ultrastructural study of cholecystokinin-immunoreactive cells and processes in area CA1 of the rat hippocampus. J Comp Neurol 233:147-158.

Henze DA, Borhegyi Z, Csicsvari J, Mamiya A, Harris KD, Buzsaki G (2000) Intracellular features predicted by extracellular recordings in the hippocampus in vivo. J Neurophysiol 84:390-400.

Jonas P, Bischofberger J, Fricker D, Miles R (2004) Interneuron diversity series: fast in, fast out-temporal and spatial signal processing in hippocampal interneurons. Trends Neurosci 27:30-40.

Kaneko T, Murashima M, Lee T, Mizuno N (1998) Characterization of neocortical non-pyramidal neurons expressing preprotachykinins A and B: a double immunofluorescence study in the rat. Neuroscience 86:765-781.

Katona I, Sperlagh B, Sik A, Kafalvi A, Vizi ES, Mackie K, Freund TF (1999) Presynaptically located CB1 cannabinoid receptors regulate GABA release from axon terminals of specific hippocampal interneurons. J Neurosci 19:4544-4558.

Kawaguchi Y, Kondo S (2002) Parvalbumin, somatostatin and cholecystokinin as chemical markers for specific GABAergic interneuron types in the rat frontal cortex. J Neurocytol 31:277-287.

Klausberger T, Roberts JDB, Somogyi P (2002) Cell type-and input-specific differences in the number and subtypes of synaptic $\mathrm{GABA}_{\mathrm{A}}$ receptors in the hippocampus. J Neurosci 22:2513-2521.

Klausberger T, Magill PJ, Marton L, Roberts JDB, Cobden PM, Buzsáki G, Somogyi P (2003) Brain state- and cell type-specific firing of hippocampal interneurons in vivo. Nature 421:844-848.

Klausberger T, Marton LF, Baude A, Roberts JDB, Magill P, Somogyi P (2004) Spike timing of dendrite-targeting bistratified cells during hippocampal network oscillations in vivo. Nat Neurosci 7:41-47.

Lamsa K, Heeroma JH, Kullmann DM (2005) Hebbian LTP in feed-forward inhibitory interneurons and the temporal fidelity of input discrimination. Nat Neurosci 8:916-924.

Llano I, Leresche N, Marty A (1991) Calcium entry increases the sensitivity of cerebellar Purkinje cells to applied GABA and decreases inhibitory synaptic currents. Neuron 6:565-574.

Losonczy A, Biro AA, Nusser Z (2004) Persistently active cannabinoid receptors mute a subpopulation of hippocampal interneurons. Proc Natl Acad Sci USA 101:1362-1367.

Maejima T, Hashimoto K, Yoshida T, Aiba A, Kano M (2001) Presynaptic inhibition caused by retrograde signal from metabotropic glutamate to cannabinoid receptors. Neuron 31:463-475.

Martin LA, Alger BE (1999) Muscarinic facilitation of the occurrence of depolarization-induced suppression of inhibition in rat hippocampus. Neuroscience 92:61-71.

McBain CJ, Fisahn A (2001) Interneurons unbound. Nat Rev Neurosci 2:11-23.

Mody I, Pearce RA (2004) Diversity of inhibitory neurotransmission through GABA(A) receptors. Trends Neurosci 27:569-575.

Nunzi MG, Gorio A, Milan F, Freund TF, Somogyi P, Smith AD (1985) Cholecystokinin-immunoreactive cells form symmetrical synaptic contacts with pyramidal and non-pyramidal neurons in the hippocampus. J Comp Neurol 237:485-505.

Nyiri G, Freund TF, Somogyi P (2001) Input-dependent synaptic targeting of $\alpha 2$-subunit-containing $\mathrm{GABA}_{\mathrm{A}}$ receptors in synapses of hippocampal pyramidal cells of the rat. Eur J Neurosci 13:428-442.

Ohno-Shosaku T, Maejima T, Kano M (2001) Endogenous cannabinoids mediate retrograde signals from depolarized postsynaptic neurons to presynaptic terminals. Neuron 29:729-738.

O'Keefe J (1976) Place units in the hippocampus of the freely moving rat. Exp Neurol 51:78-109.

O’Keefe J, Recce ML (1993) Phase relationship between hippocampal place units and the EEG theta rhythm. Hippocampus 3:317-330.

Pawelzik H, Hughes DI, Thomson AM (2002) Physiological and morphological diversity of immunocytochemically defined parvalbumin- and cholecystokinin-positive interneurones in CA1 of the adult rat hippocampus. J Comp Neurol 443:346-367.

Pinault D (1996) A novel single-cell staining procedure performed in vivo under electrophysiological control: morpho-functional features of juxtacellularly labeled thalamic cells and other central neurons with biocytin or neurobiotin. J Neurosci Methods 65:113-136.

Pitler TA, Alger BE (1992) Postsynaptic spike firing reduces synaptic $\mathrm{GABA}_{\mathrm{A}}$ responses in hippocampal pyramidal cells. J Neurosci 12:4122-4132.

Pouille F, Scanziani M (2004) Routing of spike series by dynamic circuits in the hippocampus. Nature 429:717-723.

Ramon y Cajal S (1893) Estructura del asta de ammon y fascia dentata. Anal Soc Espan Historia Natural 22:53-114.

Rudolph U, Mohler H (2004) Analysis of GABAA receptor function and dissection of the pharmacology of benzodiazepines and general anesthetics through mouse genetics. Annu Rev Pharmacol Toxicol 44:475-498.

Skaggs WE, McNaughton BL, Wilson MA, Barnes CA (1996) Theta phase precession in hippocampal neuronal populations and the compression of temporal sequences. Hippocampus 6:149-172.

Soltesz I, Deschenes M (1993) Low- and high-frequency membrane potential oscillations during theta activity in CA1 and CA3 pyramidal neurons of the rat hippocampus under ketamine-xylazine anesthesia. J Neurophysiol 70:97-116.

Somogyi J, Baude A, Omori Y, Shimizu H, El Mestikawy S, Fukaya M, Shigemoto R, Watanabe M, Somogyi P (2004) GABAergic basket cells expressing cholecystokinin contain vesicular glutamate transporter type 3 (VGLUT3) in their synaptic terminals in hippocampus and isocortex of the rat. Eur J Neurosci 19:552-569.

Somogyi P, Klausberger T (2005) Defined types of cortical interneurone structure space and spike timing in the hippocampus. J Physiol (Lond) 562:9-26.

Somogyi P, Hodgson AJ, Smith AD, Nunzi MG, Gorio A, Wu JY (1984) Different populations of GABAergic neurons in the visual cortex and hippocampus of cat contain somatostatin- or cholecystokininimmunoreactive material. J Neurosci 4:2590-2603.

Steffenach HA, Witter M, Moser MB, Moser EI (2005) Spatial memory in the rat requires the dorsolateral band of the entorhinal cortex. Neuron 45:301-313.

Thomson AM, Bannister AP, Hughes DI, Pawelzik H (2000) Differential sensitivity to Zolpidem of IPSPs activated by morphologically identified CAl interneurons in slices of rat hippocampus. Eur J Neurosci 12:425-436.

Toledo-Rodriguez M, Blumenfeld B, Wu C, Luo J, Attali B, Goodman P, Markram H (2004) Correlation maps allow neuronal electrical properties to be predicted from single-cell gene expression profiles in rat neocortex. Cereb Cortex 14:1310-1327.

Vanderwolf $\mathrm{CH}$ (1969) Hippocampal electrical activity and voluntary movement in the rat. Electroencephalogr Clin Neurophysiol 26:407-418

Vida I, Halasy K, Szinyei C, Somogyi P, Buhl EH (1998) Unitary IPSPs evoked by interneurons at the stratum radiatum-stratum lacunosummoleculare border in the CA1 area of the rat hippocampus in vitro. J Physiol (Lond) 506:755-773.

Wilson MA, McNaughton BL (1993) Dynamics of the hippocampal ensemble code for space. Science 261:1055-1058.

Wilson RI, Nicoll RA (2001) Endogenous cannabinoids mediate retrograde signalling at hippocampal synapses. Nature 410:588-592.

Zar JH (1999) Biostatistical analysis. Upper Saddle River, NJ: Prentice-Hall. 